\title{
ABOMINABLE SNOWMEN
}

\section{The Present Position}

\author{
By William C. Osman Hill
}

On ancient Indian maps the mountainous northern frontier is referred to as the Mahalangur-Himal, which may be translated as the mountains of the big monkeys. In view of recent reports one naturally wonders whether the big monkeys referred to were the large langurs (Semnopithecus), which are known to ascend to the hills to altitudes of 12,000 feet, or to something still larger, which ranges to even higher altitudes.

Ancient Tibetan books depict many representatives of the local fauna quite realistically, recognizably and in their correct natural settings. Among these, in addition to ordinary arboreal monkeys, is represented a large, erect, rock-dwelling creature of man-like shape, but covered with hair (Vlček, 1959). One wonders whether this could relate to the cryptic being that has come to be known from the reports of Himalayan explorers and their Sherpa guides as the Abominable Snowman.

Legends of large or smaller hairy man-like creatures which walk erect, possess savage dispositions and cause alarm to local humanity are rife in many parts of Asia (witness the stories of Nittaewo in Ceylon, Orang-pendek in Malaya, Almas in Mongolia) and even in much more distant places (Sasquatch in British Columbia, Bigfoot in California and the Didi of the Guianan forests), to say nothing of similar legends from various parts of Africa. Among these the Yeti, or Abominable Snowman, is perhaps the most persistent.

We are, however, at the present time, unaware of the real nature or origin of any one of these, though scores of supposedly correct solutions have been put forward in explanation by both zoologists and laymen.

Without entering deeply into the history of our acquaintance with the Himalayan representatives of this catalogue of ogres, I am concerned here rather with presenting and weighing the evidence for its existence and with deducing pointers as to its possible nature. The historical development of our knowledge, such as it is, has already been fully discussed elsewhere (notably by Izzard, 1955 ; Ley, 1955 ; Heuvelmans, 1955, 1958 a and b; and Tchernine, 1961).

Firstly then as to the geographic range of the "snowman"; reports have now been received from a wide area extending from 
the Indo-Burmese frontier westwards to the Karakoram, with additional outliers, according to Russian scientists, in the Pamirs, the Caucasus and Mongolia. All the reports to date indicate restriction to high altitudes, 16,000 feet and above. Indeed much evidence has been observed above the snow-line. This has resulted in the designation "snowman" and has fostered the erroneous impression that the eternal snows are its permanent home.

Secondly some comments are worth while on the numerous designations of the snowman. The term "abominable snowman" is due to a misinterpretation of its native name, metehkangmi which, in a cable sent by Colonel Howard Bury from the 1921 Mount Everest Expedition to Calcutta, was distorted to metch-kangmi, the translation of which naturally caused some confusion and difficulty, but was finally interpreted by H. Newman as "abominable snowman" on the assumption that metch or metchete was the Tibetan term for filthy or dirty, while kang meant "snow" and $m i$ " man". In fact the term $m e h$ is Nepalese for animal or creature and it has been ascertained that the original cable used the name mehteh, the full name being mehteh Kang-Mi, i.e. " man-like wild creature " in contrast to other Nepalese terms such as Dzu-teh (bear-like, or more probably bear-sized creature*) and $Y$ eh-teh (little man creature). It is clear from this that at least three different entities are recognized by the indigenes of which two, at any rate, are supposedly man-like in habitus and the third bear-like, at least in size. Whether these represent three different species, products of sexual dimorphism, or individuals of the same form at different periods of its life-span, remains to be determined.

In other areas than the Nepalese Himalaya different names are prevalent for what appear to be similar apparitions, e.g. Gent (1915) mentions the sogpa or jungli admi in Sikkim, whilst the Mongolian representatives are termed almas.

Evidence for the existence of some creature or creatures unknown to science may be summarized under the following headings :-

I. Reports
A. Native.
B. Western.

\section{Physical Evidence}

(a) Foot-tracks, or photographs or plaster casts of such.

* The term Dzu means " livestock" and $d z u$-teh evidently refers to the alleged habit of this giant species of attacking domesticated yak. 
(b) Parts of the creature, e.g. skins, or parts of skins, hairs, bones, ectoparasites from skins.

(c) Products of metabolism, e.g. faeces-indications of diet, endoparasites, samples of own hairs or that of its prey.

\section{Corollary Evidence}

(a) Reports of vocal utterances.

(b) Observations of physical objects displaced by the creature in its peregrinations.

(c) Literary references and objets d'art.

Reports given by native Sherpas who have accompanied the various Everest expeditions, together with those of Tibetan monks attached to the numerous Gompas in the area concerned, may be summarized briefly as follows. They declare that some of the tracks observed by Everest climbers are the spoor of creatures they label as $d z u$-teh, meh-teh and yeh-teh, in order of descending stature. There is undoubtedly some confusion in their minds as to the nature of these entities, though all consistently agree-and independently in different places, without any possibility of collusion - that these are genuine and normal denizens of the local rocks and scrub. In fact, to the local monk or herdsman, the interest of Europeans in these phenomena comes as a surprise, for to them the manifestations are commonplace.

The giant form or $d z u$-teh is alleged to be something the size of a bear, though not a bear-an animal which they know well-at least in the areas where it occurs. (There are several species of bear in the general area, viz. the Himalayan Black Bear, the Isabelline Bear or Red Bear, a local race of Ursus arctos, and the much rarer Blue Bear, $U$. pruinosus.) Attributes of the $d z u$-teh, apart from its large size, are its great strength, predatory nature and its predilection for attacking the domestic yak. All agree, moreover, that the $d z u-t e h$ is a thing of flesh and blood, not a spirit or demon.

The Meh-teh is the Teh associated with man. This may mean either that it resides in the vicinity of human settlements, or that it is dangerous to man, or more likely that it is man-like in size and/or shape. It is stated to affect rocky terrain and to feed on the calling hare or pika (Ochotona). It is stated to lie in wait near a crevice where the pikas abound and to seize them, disembowel them and eat the rest of the animal. It is of some significance that Stonor (1955) records having himself met with accumulations of pika viscera in circumstances which could have verified this behavioural pattern. Another attribute is the 
loud yelp it is said to emit. Occasionally the animal descends the valleys, especially in winter and has been heard giving this call, but it is shy of humans and not apparently aggressive.

As regards the $Y e h-t e h$, or true Yeti, there is some confusion with the last. Stonor was at one time under the impression that the two names were interchangeable; but there is some evidence that the two are different and occupy different ecological niches. At any rate the name refers to a creature of smaller stature, equivalent to a 14-year old boy. Like the Meh-teh, it normally progresses in the erect posture, emits a chattering note and is partly carnivorous. It prefers smaller fry than the larger Tehs, seeking its food near streams or marshes, and under stones, for it is said to be fond of frogs, crustacea and molluses.

There are numerous native reports of sightings of one or more of the Tehs, more particularly by Tibetan monks, Sherpa herdsmen and especially by the celebrated Sen Tensing, who accompanied Hillary to the summit of Everest. These sightings are tabulated by Heuvelmans (1958a).

Reports from Europeans who have visited or explored in the areas are, for the most part, based upon native interpretations of the remarkable trails of footprints that have been encountered by almost every Himalayan expedition, since first commented upon by Colonel L. A. Waddell in 1887. These trails indicate an animal progressing bipedally with a definite stride. They will be considered more thoroughly hereafter.

There are also reports of actual sightings by Europeans. Earliest of them was H. J. Elwes, F.R.S., a noted Himalayan explorer, botanist and zoologist. He is reputed to have seen and made notes and sketches of a "Yeti" in 1906 in Tibet. His original notes were seen by members of the Royal Botanical Gardens before 1914, as well as by fellows of the Royal Geographical Society and members of his own family. Unfortunately they have not been found among his effects, despite diligent search.

In 1915 Elwes made a communication to the Zoological Society, not, however, on his own observations but reporting a letter he had received from a friend, J. R. O. Gent, a Forest Officer of Darjeeling. Gent reported the existence of a strange animal in Sikkim called the jungli admi or sogpa, of about 4 feet height covered with long, yellow-brown hair, the colour of a rhesus monkey. Gent does not claim to have seen it, but records one having worried the coolies working in the forest below Phalut. He describes the tracks left in the snow, and declares it is not the large Nepal Langur. 
Other sightings by Europeans have been incorporated in Heuvelman's table, from which the undermentioned are excerpted :-

\begin{tabular}{|c|c|c|c|c|}
\hline & D ATE $_{\text {AT }}$ & LoCALITY & OBSERVER & Description and Remarks \\
\hline 1 & About 1913 & Tibet & $\begin{array}{l}\text { H. Knight, English } \\
\text { explorer }\end{array}$ & $\begin{array}{l}\text { Gorilla like, with powerful chest, } \\
\text { long arms ; feet flat. Ran } \\
\text { sometimes erect, sometimes on } \\
\text { all fours. }\end{array}$ \\
\hline 2 & 1925 & $\begin{array}{c}\text { Zemu Gap } \\
\text { (Sikkim) }\end{array}$ & $\begin{array}{l}\text { N. A. Tombazi, } \\
\text { Italian photo- } \\
\text { grapher, a sceptic }\end{array}$ & Silhouette of an unclothed man. \\
\hline 3 & August 1942 & $\begin{array}{l}\text { Sikkim-Bhutan } \\
\text { frontier }\end{array}$ & $\begin{array}{l}\text { S. Rawicz, Polish } \\
\text { Officer }\end{array}$ & $\begin{array}{l}\text { Two bipedal creatures observed, } \\
2 \frac{1}{2} \text { m. high, covered with } \\
\text { reddish hair with grey reflec- } \\
\text { tions ; chest powerful. Account } \\
\text { has been discredited by re- } \\
\text { viewers of his book The Long } \\
\text { Walk, but Rawicz in litt. (1960) } \\
\text { maintains truth of his asser- } \\
\text { tions. }\end{array}$ \\
\hline 4 & 11th June, 1948 & Zemu Gap & $\begin{array}{l}\text { A. Thorberg and } \\
\text { J. Frostis, Nor- } \\
\text { wegian prospec- } \\
\text { tors }\end{array}$ & $\begin{array}{l}\text { Two anthropoids of human sta- } \\
\text { ture, covered with brown hair, } \\
\text { except face. A long tail } \\
\text { present! Authors untraced ; } \\
\text { ? bogus. }\end{array}$ \\
\hline 5 & $\begin{array}{l}\text { 10th to } 13 \text { th } \\
\text { August } 1957\end{array}$ & $\begin{array}{l}\text { Valley of Baliand- } \\
\text { Kiik, Pamir }\end{array}$ & $\begin{array}{l}\text { A. G. Pronin, Rus- } \\
\text { sian engineer }\end{array}$ & $\begin{array}{l}\text { Bipedal anthropoid covered with } \\
\text { reddish-grey hair; arms very } \\
\text { long. } \\
\text { At first discredited by Russian } \\
\text { press, later rehabilitated (vide } \\
\text { Porschnieff, 1958). }\end{array}$ \\
\hline 6 & October, 1960 & W. Lahoul region & $\begin{array}{l}\text { A. Cram, Scots } \\
\text { Magistrate from } \\
\text { Nairobi }\end{array}$ & $\begin{array}{l}\text { Said to have seen a snowman } \\
\text { and photographed footprints } \\
\text { at } 18,000 \mathrm{ft} \text {. (Daily Telegraph, } \\
\text { 21st October, 1960.) }\end{array}$ \\
\hline
\end{tabular}

Coming now to physical evidence, we may deal first with the foot-tracks, which are the phenomena principally responsible for bringing the legendary " snowman" to the notice of western scientists.

It would be tedious to catalogue all the reports of bipedal tracks in the snow that have been reported and/or photographed by Himalayan explorers. Suffice it to say that the reports evoked considerable controversy, especially from 1921 onwards. Most zoologists emphatically declared they must have been made by bears; a minority were inclined towards the large Himalayan langur (Semnopithecus entellus schistaceus) or one of its congeners. That some of the tracks were due to bears there can be little doubt. That they were produced by any quadrupedal tailed monkey, especially a langur, there is not the slightest morphological evidence, since the langur has a narrow, elongated foot quite unlike the so-called Yeti prints, and, moreover, would probably leave some impression of its tail. Moreover 
no langur progresses bipedally over the distances reputed for Yeti trails-neither, for that matter, does a bear. Bears though capable of erect progression do so only in a shuffling fashion and not by raising the feet alternately in a stride.

Matters were brought to a head in 1951 when Eric Shipton's photographs of a particularly clear set of tracks were published in the Illustrated London Neres. These were taken on the Menlung glacier and each imprint measured $12 \frac{1}{2}$ in. long by $6 \frac{1}{2}$ to $7 \frac{1}{2}$ in. across. The imprints were well apart, indicating the distance of stride. Their clarity, especially the distinctness of the imprint of the big toe, the other toes, the relative pressures and method of displacement of the substratum, and finally the regularity of the trail, did much to dispose of some of the controversial points and to establish that they were the product of neither bear, leopard nor langur.

Some allowance has, of course, to be made for distortion as time had elapsed between the passage of the creatures and the arrival of the explorers. Critics have used this argument in attempts to condemn the belief in an anthropoid origin or their being the product of an animal hitherto unknown to science.

Even this criticism was dispelled by the report of Bordet (1955), a French geologist, who accompanied the two French expeditions to Makalu (1954, 1955). In May 1955 Bordet, with a sherpa and several porters, was descending the Barun valley, when his trail crossed that of a postman who, on account of his fear of the Yeti, was accompanied by a friend. Bordet reported recent heavy snow which was still soft. Resuming their way the following day, Bordet's company encountered fresh snow at the limit of the rhododendron forest, and here the tracks of the postman and his companion were still evident. Then they came across another trail which crossed the col, and which Bordet's sherpa proclaimed to be a Yeti trail. Examination proved the trail to be more recent than the postman's, so it had been made either the previous evening or possibly earlier that same morning. The tracks evoked no surprise as plenty of others had been met with on the expedition, though none had been so fresh. They indicated a pair of feet 10 to $15 \mathrm{~cm}$. deep in the snow, and that at certain points the animal had evidently jumped to avoid obstacles or difficult spots. Over 3,000 impressions were seen before visibility was reduced by fog-much to the relief of the porters who were manifestly afraid of the Yeti. Descriptions given of the footprints agree with those of previous observers, i.e. with a large first toe set slightly back from the others, and with no trace of claws in 
front (invariably present in bear tracks), and without any evidence of fore-feet. The axes of right and left impressions were nearly parallel or slightly divergent in front. In the best prints ridges of snow were visible between the toes. Stride was approximately $50 \mathrm{~cm}$. A second set of tracks was observed leading to a lake, where the animal had evidently stopped to drink.

Plaster casts of alleged Yeti footprints have been made by Peter Byrne on one of Slick's expeditions, whilst Tschernezky (1960) has, by making life-size photographic enlargements from Shipton's best impressions, reconstructed in plaster the form of the foot responsible for them. His results are suggestive of a large primate foot rather than that of a bear.

A few comments are necessary on the varying number of toes reported by different observers. Shipton's best show five, though the three smallest outer toes are bunched together. Bordet's showed only four as did several others. Here again there may have been poor separation between the small lateral digits. Byrne's plaster cast shows four distinct toes all aligned together in the same axis with the largest on one side. This could feasibly have been due to a bear where the fifth digit is normally larger than the first. Some descriptions, e.g. Gent's, affirm that the toes are directed backwards and the suggestion has been made that this is due to the animal scrambling on its knees so that the upper surface of the foot leaves the impression. But that would not account for such clear-cut impressions as those referred to by Shipton and Bordet, not to mention many others.

The next category of physical evidence relates to material alleged to be derived from the bodies of departed Yetis. Among these are mummified bodies, skins or parts of skins, hair, bones, and ectoparasites. Reports are also in existence of the capture of living Yetis. Of the latter there is the record of Prince Peter of Greece, confirmed later by von Nebesky-Wojkowitz. Large ape-like creatures had been in the habit of drinking during the night at a cistern at the mouth of the Jalap valley, Sikkim. The villagers doped the cistern with fermented liquor (chang) and one of the beasts collapsed in a drunken stupor, whereon it was lashed to a pole. On sobering it regained its strength and escaped. Another living specimen was supposedly on exhibit in a zoo in Shigatse, Tibet. But later investigation proved this to be nothing but a Gibbon (teste Stonor). In the Russian documentation of yeti-lore a report is included from Professor Tsiw Pen of the Chinese Academy of Science, of the 
capture of a $M i-G e(=M i g o$ ) in the Choni-syan region of Tibet and its hide is said to be preserved in a temple at Hufash-endyan. Other mummified bodies are rumoured to be housed in various Tibetan monasteries.

Another report dating from 1900 is to the effect that during the laying of the telegraph line from Lhasa to Kalimpong, a Yeti was encountered and shot. Its body was sent to Sir Charles Bell, then Political Officer in Sikkim, by whom it was forwarded to India. Presumably it was lost en route as no more was heard of it.

Peter Byrne informed me that on the last (3rd) Slick expedition, he had obtained a purse from a Tibetan monk who declared it to be made from Yeti skin. I have not seen this and have not yet received any hairs from it. Presumably it is being investigated in the United States.

Of all the physical objects of allegedly Yeti origin, attention has been directed most of all to the conical caps kept and used for ceremonial purposes at several monasteries in Nepal, notably at Pangboche and Kumjung. The monks declare these to be the "scalps" of Yetis. Much time and trouble has been spent over them, and more especially on hairs plucked from them.

Rather non-commital reports had been given on hairs submitted to a number of authorities by the Daily Mail expedition of 1954, whilst Wood-Jones had come to the conclusion, based on photographs which showed the peculiar hair tracts on the "scalp", that it had been moulded from the hump of a Zebu (Bos indicus). Hairs suggested ungulate origin though yak was ruled out. Another hypothesis that has been considered was that the "scalp" was the stretched and dried scrotum of a Yak. This was disproved on the discovery that the yak's scrotum is naked, except for a few short hairs at its root.

Hillary succeeded in obtaining the Kumjung "scalp" on loan, enabling him to place it before committees of experts in Chicago, London and Paris in December, 1960. Hillary also submitted a cap he had himself moulded from the skin of a Serow (Capricornis sumatraensis), a wild goat-antelope. Strange as it may appear, the curious hair pattern of the supposed yeti scalp was reproduced accurately* and, together with microscopic observations on the hairs from both, it appeared that they could have originated from the same or related species of Ungulate. These observations, coupled with (i) the fact that a

* This had already been proved possible by Biswas (in litt.). 
couple of skins of the Blue Bear (Ursus pruinosus) obtained by his expedition had been purchased on the assumption that they pertained to Yeti and (ii) a personal opinion of Hillary's that all the described Yeti footprints could be explained as having been produced by foxes, would seem to have rung the deathknell of the whole Yeti myth.

It must be admitted that the " scalps " had long been suspect, though how caps made from Serow (which do not occur naturally in Western Nepal) came to the monasteries is unknown. But doubtless trading with areas where it occurs has occurred for a long time. It is known, for example, that the Abors, a tribe living in the N.E. corner of Assam use helmets made of wild goat skin for war purposes ( fide Biswas, 1960, in litt.).

Nevertheless judgment of the whole Yeti issue on the basis of the debunked "scalp " and the other " evidence " produced by Hillary appears rather hasty. Even with respect to the "scalps ", I would point out that certain significant conclusions are drawn in a very detailed report sent to me by Miss Marca Burns, of the Textile Industries department of Leeds University, to whom were submitted samples of skin and hair from the Kumjung "scalp". Although the sample showed obvious similarity to the sample of Serow skin, it did not prove identical. The differences were mostly of a kind which could feasibly occur between different individuals of the same species or between different parts of the same animal. Certain wider differences, however, could not be so accounted for, and could be explained only on the assumption that they originated from different species or even genera. No clear resemblance was shown to material from either Ursus pruinosus or $U$. arctos and only slight similarities to Yak. The only feature recalling simian character is the symmetrical arrangement of pigment granules in some of the hairs from the "scalp "- not seen in the Serow sample.

More significant still, however, was the recovery of mites infesting both the Kumjung article and the artificial cap of Serow skin. Mites from the latter proved to belong to a common species, Chorioptes bovis, well known from various ruminants. Those from the Kumjung sample proved to be quite unusual in respect of the sculpturing of the cuticle, the arrangement and conspicuousness of the hairs and the size of the limbs-all of which are different from conditions in Chorioptes. So far these parasites remain unidentified; they may well be important in diagnosis of the nature of the host, for it is well established that parasites are remarkably restricted in their host relationship.

Other physical evidence in the shape of bones may be briefly 
dismissed as all have proved to pertain to known mammalian species. A mummified hand kept at the Pangboche monastery proved to be human, albeit its metacarpals in the available photographs betrayed some features met with in anthropoid apes. A mummified forearm with incomplete hand collected in a cave on Makalu by one of the Slick expeditions proved to belong to a large feline-almost certainly Snow-Leopard.

Remaining physical evidence comprises the products of the creature's metabolism, and this is so far limited to samples of its droppings (faeces). The Daily Mail expedition reported finding heaps of excrement along the Yeti trails located by them. Stonor twice discovered droppings of a large animal containing fur, rodents' bones and quantities of earth. Unfortunately none was collected for expert examination and the scientific world had to be content with the rough and ready local examination by the expedition's members. The droppings were said to differ from those of wolves and bears. Gerald Russell seems to have been the main investigator; the voided hairs were stated to agree with those of the Pika (Ochtona) thus apparently confirming the Sherpa's statements of the Yeti's diet. How this could be asserted without microscopic examination is almost incredible.

More recently the author received dried, supposedly faecal, material collected near a stream by Peter Byrne on one of Slick's expeditions. It presumably originated from the small type of Yeti which supposedly fossicks around mountain streams for frogs, crabs or other crustacea. Analysis of the sample indicated an omnivorous diet, as it included digested vegetable debris-leaf skeletons, stalks and fruit-skins, mixed with fragments of caterpillars, grasshoppers and earthworms. Some very fine hairs were present, but did not tally with Ochtona hairs though reminiscent of some small rodent or insectivore. There is no positive evidence of human origin ; it could conceivably be a bird's regurgitation, though vegetable remains render this unlikely.

An enormous faecal sample received by the author from N.W. California, alleged to pertain to the "Bigfoot", is quite another story and need not detain us here.

Of corollary evidence we have the native descriptions (and imitations) of the voice of the elusive snowman-all of which agree in minute detail. Secondly there come the observations of physical objects displaced by the creature. Here mention should be made of :

(i) Disturbances in the snow other than footprints-such as 
the impressions of the animal's posterior as it sat or fell upon its buttocks when negotiating a crevice.

(ii) Native assertions, presumably relating to the small or true $Y e h$-teh, of its habit of turning over stones in shallow streams when searching for insect food. Peter Byrne saw evidence of this ; undisturbed stones are covered superficially with algae, it is therefore easy to see those which have been disturbed.

(iii) N. G. Dyhrenfurth, a member of the second Swiss Everest expedition of 1952, claims that a Yeti interfered during the night with his tent (at 23,000 feet). He was awakened by a sense of suffocation and the noise of something crunching the snow accompanied by stertorous breathing and a musky smell. Outside he found nothing - not even footprints next morning, for the snow had been packed hard by the strong gale. There is thus no proof this was a Yeti, but that was the explanation given by the Sherpas.

The final items of corollary evidence are literary references and objets d'art. The principal literary references have already been mentioned in the introduction (p. 86), but there are others, though these relate rather to the Almas than the Himalayan snowman, so they need not concern us here.

A remarkable ritual Buddhist mask of papier-maché of obviously oriental origin was recently discovered in the museum of the Moscow puppet-theatre. In an article by R. S. R. Fitter (1960) this is figured and described as having come from Mongolia in 1940, but possibly originating in Tibet some 150 years ago. The mask depicts a tusked anthropoid and, in the opinion of S. M. Uspenski, it could have been modelled on the basis of a mummified head of an abominable snowman, as it is too realistic to be conceivably based purely on imagination.

Summing up, then, it would seem that as far as physical evidence goes, apart from footprints, no absolute proof has been evoked for the existence of any animal in the Himalayan area unknown to science. There are pointers in plenty, but the evidence is often susceptible of alternative explanation, is lacking in essential detail, or productive only of non-committal opinion.

It stands to reason, however, that the data considered above suggest that something still awaits explanation. The tracks in snow photographed by Shipton and those recorded by Bordet are very difficult to explain on the assumption of their being produced by bears, foxes, snow-leopards, giant panda or other suggested originators; furthermore they are far too distinct to 
be brushed aside, as has been done by Peissel (1960), as caused by Himalayan guides whose feet are protected by being wrapped in rags to guard against the cold, though doubtless impressions so caused are common enough.

For the rest, the legend of the Snowman is based largely on local tradition and the testimony of eyewitnesses. The latter may have been mistaken, and the suggestion has been made that sightings, especially by Europeans, are to be explained as due to psychological effects induced by high altitudes or based on encounters with religious ascetics who dwell in caves on the mountainsides. Such personages doubtless exist, but they do not account for all the recorded phenomena.

There remains then a complex of phenomena that still await scientific explanation. Without categorically stating which of several alternatives is the most likely, the conclusions arrived at by $\mathbf{E}$. Wyse-Dunant, leader of the first Swiss Everest Expedition (1952) would seem yet to hold good. These are (i) the phenomena point to a plantigrade mammal capable of bipedal progression and of jumping ; (ii) it does not live alone, but in small family groups. A further point would also seem to emerge, viz. that searchers for the snowman have been looking in the wrong places. It is inconceivable that the region of perpetual snow is the permanent home of any large mammal, and such terrain is presumably crossed only under the stress of circumstances, when the creature is forced to cross to another feeding ground in an adjacent valley. The permanent home is undoubtedly the dense rhododendron thickets of the lower parts of the valleys, and it is here that future search should be especially directed.

\section{BIBLIOGRAPHY}

B1swas, B., 1960. In litt.

Bordet, P., 1955. Traces de yéti dans l'Himalaya. Bull. Mus. Nat. Hist. Nat. Paris, 27, 433-9.

Burns, Marca, 1961. Report on the Khumjung yeti scalp. MSS. unpublished.

ELwEs, H. J., 1915. On the possible existence of a large ape unknown to science in Sikkim. Proc. Zool. Soc. London, 294.

Frrter, R., 1960. Mask provides new clue to the snowman. The Observer, 23rd October 1960.

Greece, Peter, Prince of, 1958. Chevauché Tibetain, Paris, Nathan.

Heuvelmans, B., 1955. Sur la piste des bêtes ignorées. Paris, Plon, 2 vols.

- 1958a. Oui, l'homme-des-neiges existe. Sciences et Avenir, No. 134, 174-9 and 220.

1958b. On the track of unknown animals. London, Hart-Davis.

Izzand, R., 1955. The abominable snorman adventure. London, Hodder and Stroughton.

LEY, W., 1955. Salamanders and other wonders. New York, Viking Press. 
Nebeskx-WoJkowitz, Rene De. Oracles and Demons of Tibet: The Cult and Iconography of the Tibetan Protective Deities. The Hague, 1956, 682 pp., 20 illus.

Peissex, M., 1960. The abominable snow job. Argosy, December, 1960, 81-4.

Porschniefr, B. S., 1958. Komsomolskaya Pravda, 7th July, 1958.

Rawicz, S., 1956. The Long Walk. London, Constable.

Stonor, C., 1955. The Sherpa and the Snowman. London, Hollis and Carter.

Tchernine, O., 1961. The Snozman and Company. London, R. Hale, Ltd.

Tschernezsky, W., 1960. A reconstruction of the foot of the "abominable snowman ". Nature, London, 186, 496-7.

VLČEK, E., 1959. Old literary evidence for the existence of the "snowman" in Tibet and Mongolia. Man, 59, 133-4.

Waddely, L. A., 1899. Among the Himalayas. London, Constable and Co. 